\title{
Comparison of fermentation of diets of variable composition and microbial populations in the rumen of sheep and Rusitec fermenters. II. Protozoa population and diversity of bacterial communities ${ }^{1}$
}

\author{
M. E. Martínez, ${ }^{\star} \dagger$ M. J. Ranilla, ${ }^{\dagger} \dagger$ M. L. Tejido, ${ }^{*} \dagger$ C. Saro, ${ }^{*} \dagger$ and M. D. Carro ${ }^{*} \dagger^{2}$ \\ *Departamento de Producción Animal, Universidad de León, 24007 León, Spain \\ †Instituto de Ganadería de Montaña (CSIC-ULE), Finca Marzanas s/n. 24346 Grulleros, León, Spain
}

\begin{abstract}
Four ruminally and duodenally cannulated sheep and 8 Rusitec fermenters were used to determine the effects of dietary characteristics on microbial populations and bacterial diversity. The purpose of the study was to assess how closely fermenters can mimic the differences between diets found in vivo. The 4 experimental diets contained forage to concentrate $(\mathrm{F}: \mathrm{C})$ ratios of $70: 30$ (high forage; HF) or 30:70 (high concentrate; HC) with either alfalfa hay (A) or grass hay $(G)$ as the forage. Total bacterial numbers were greater in the rumen of sheep fed HF diets compared with those fed HC diets, whereas the opposite was found in fermenters. The numbers of cellulolytic bacteria were not affected by $\mathrm{F}: \mathrm{C}$ ratio in any fermentation system, but cellulolytic numbers were 2.7 and 1.8 times greater in sheep than in fermenters for $\mathrm{HF}$ and $\mathrm{HC}$ diets, respectively. Neither total bacterial nor cellulolytic numbers were affected by the type of forage in sheep or fermenters. Decreasing F:C ratio increased total protozoa and Entodiniae numbers in sheep by about 29 and $25 \%$, respectively, but it had no effect in fermenters. Isotrichidae and Ophryoscolecinae numbers in sheep were not affected by changing $\mathrm{F}$ : $\mathrm{C}$ ratio, but both disappeared completely from fermenters fed $\mathrm{HC}$ diets. Total protozoa and Entodiniae numbers were greater in sheep fed A diets than in those fed G diets, whereas the opposite was found in fermenters. Results indicate that under the conditions of the present study, protozoa population in Rusitec fermenters was not representative of that in the rumen of sheep fed the same diets. In addition, protozoa numbers in fermenters were 121 and 226 times
\end{abstract}

\footnotetext{
Received November 23, 2009.

Accepted April 25, 2010.

${ }^{1}$ Funding was provided by the Spanish Ministerio de Educación y Ciencia (project AGL2004-04755-C02-01) and the Consejería de Educación de la Junta de Castilla y León (Ref. GR158). M. E. Martinez and C. Saro gratefully acknowledge the receipt of scholarships from the Ministerio de Educacion y Ciencia of Spain (AP2005-1797 and AP 2006-03049, respectively).

${ }^{2}$ Corresponding author: mdcart@unileon.es
}

lower than those in the sheep rumen for $\mathrm{HF}$ and $\mathrm{HC}$ diets, respectively. The automated ribosomal intergenic spacer analysis of the $16 \mathrm{~S}$ ribosomal DNA was used to analyze the diversity of liquid- and solid-associated bacteria in both systems. A total of 170 peaks were detected in the automated ribosomal intergenic spacer analysis electropherograms of bacterial pellets across the full set of 64 samples, from which 160 were detected in at least 1 individual from each system (sheep or fermenter). Diversity of liquid-associated bacterial pellets was greater with $\mathrm{G}$ diets in fermenters but seemed to be unaffected by diet in sheep. Bacterial diversity in solid-associated bacteria pellets was greater for G diets compared with A diets in sheep and fermenters. Different conditions in the fermenters compared with sheep rumen might have caused a selection of some bacterial strains.

Key words: sheep, Rusitec, protozoa, bacterial diversity

\section{INTRODUCTION}

The rumen is an anaerobic microbial ecosystem that is inhabited by a complex microbial population including bacteria, protozoa, fungi, and archaea. The study of microbial ecology is complicated by daily fluctuations in the environment, microenvironments within the rumen, and the effects of animal physiology on the rumen (Ziemer et al., 2000). These difficulties have led to the development of in vitro techniques that intend to model ruminal fermentation, thereby allowing studies under well-controlled conditions. As pointed out by Ziemer et al. (2000), to be an adequate experimental tool, an artificial rumen should mimic the natural rumen in several ways, including the physical environment (temperature, $\mathrm{pH}$, turnover rates, and so on) and the maintenance of key microbial populations. Ideally, the composition of microorganisms in an in vitro system should be representative, in terms of quantity and quality, of that found in the rumen of the host animal. Although there are multiple in vitro techniques available, ruminal fer- 
menters appear to be the most suitable for studying the ruminal ecosystem.

One of the problems associated with fermenters is the maintenance of an active protozoal population. Protozoa survival is influenced by liquid turnover rate and by feeding frequency, among other factors (Teather and Sauer, 1988; Mansfield et al., 1995; Ziemer et al., 2000). Dilution rates of more than 2 turnovers per day have been reported to decrease protozoa numbers in dual-flow continuous culture fermenters (Mansfield et al., 1995; Ziemer et al., 2000), and Teather and Sauer (1988) showed that changing feeding frequency from continuous to twice daily led to decreased protozoal counts in fermenters with continuous independent flow of liquid and particulate matter. To date, no fermenters exist that can maintain protozoa numbers similar to those found in the rumen, although a promising system has been recently described (Muetzel et al., 2009). However, most studies have focused on total numbers of protozoa and proportion of Holotricha, and studies on the diversity of ciliate protozoa in fermenters fed diets of variable composition are limited.

An additional problem is that the total composition of ruminal microbial communities cannot be studied with traditional cultivation techniques. In recent years, molecular fingerprinting techniques such as denaturing gradient gel electrophoresis (DGGE), single strand conformation polymorphism (SSCP), terminal RFLP, and automated ribosomal intergenic spacer analysis (ARISA) have been used to assess the richness and diversity of ruminal microbial communities (Ziemer et al., 2000; Martínez et al., 2009b; Ramos et al., 2009). The application of these techniques constitutes a useful tool to evaluate whether fermenters produced a microbial community that represents the natural ecosystem in the rumen. Nevertheless, to date little work has been done to compare microbial populations assessed by molecular techniques in fermenters with those in the rumen, and the results are contradictory. Ziemer et al. (2000) compared microbial populations in the rumen of a donor cow with those developed in dualflow continuous culture fermenters receiving the same diet fed to the cow. Total rRNA concentration was 1.5 times greater in the fermenters than in the cow, and the average abundance of Bacteria, Archaea, and Eukarya in the fermenters was 176,172 , and $3 \%$ of that found in the rumen, indicating changes in microbial populations over the incubation period. More recently, Muetzel et al. (2009) developed a fermenter aimed to maintain an active protozoal population and analyzed the relative abundance of microbial populations by slot blot hybridization. Total rRNA concentration in the fermenters was lower than in the donor cows, and the proportions of the rRNA from Bacteria, Archaea, and
Eukarya in the fermenters were 96,200 , and $107 \%$ of those found in the cows. To our knowledge, only Prevot et al. (1994) analyzed changes in microbial populations in Rusitec fermenters over the incubation period, and they concluded that fermenters could not maintain microbial populations in conditions comparable to those encountered in vivo because proportions of bacteria and protozoa decreased to 30 and 1\%, respectively, of those in vivo. Clearly, the operating conditions in each type of fermenter can affect the evolution of microbial populations over the incubation period. Moreover, the microbial community fluctuates with changes in feed composition, but the host animal also influences the microbial population in the rumen as well as the interactions within the community, and such influences cannot appropriately be mimicked in vitro (Firkins and $\mathrm{Yu}, 2006)$.

The objective of this study was to assess to what extent Rusitec fermenters can be used to characterize the effects of diet on microbial populations and bacterial diversity. For that purpose, the effects of 4 diets differing in forage to concentrate $(\mathbf{F}: \mathbf{C})$ ratio and type of forage (FOR) on microbial populations and bacterial diversity were assessed in sheep and the results were compared with those observed in Rusitec fermenters given the same diets.

\section{MATERIALS AND METHODS}

Diets, animals, fermenters, and experimental procedures are described in a companion paper (Martínez et al., 2010) and are summarized below.

\section{Diets}

Four total mixed diets were formulated according to a $2 \times 2$ factorial arrangement of treatments. The diets had F:C (DM basis) ratios of 70:30 (high forage; HF) or 30:70 (high concentrate; HC) with either alfalfa hay (A) or grass hay $(\mathbf{G})$ as forage and were designated as HFA, HFG, HCA, and HCG. Ingredients and chemical composition of diets are shown in Martínez et al. (2010).

\section{In Vivo Trial: Animals and Experimental Procedure}

Four ruminally and duodenally cannulated Merino sheep $(58.5 \pm 3.16 \mathrm{~kg}$ of BW) were used. Animals were cared for and handled in accordance with the Spanish Animal Care Regulations (Spanish Government, 2005), and the experimental protocols were approved by the León University Institutional Animal Care and Use Committee. Sheep were housed in individual pens and had continuous access to fresh water and vitamin- 
mineral block over the experimental period. Diets were offered to the animals twice daily (0800 and $2000 \mathrm{~h}$ ) at a daily rate of $56 \mathrm{~g}$ of $\mathrm{DM} / \mathrm{kg}$ of $\mathrm{BW}^{0.75}$ to minimize feed selection. This level of intake was estimated to meet $1.2,1.1,1.4$, and 1.3 times the energy maintenance requirements of the experimental sheep for HFA, HFG, HCA, and HCG diets, respectively (NRC, 1985).

The experimental design was a $4 \times 4$ Latin square, and each 25-d experimental period consisted of $14 \mathrm{~d}$ of dietary adaptation and $11 \mathrm{~d}$ (d 15 to 25) of sample and data collection. On d 15 of each period, about $400 \mathrm{~g}$ of ruminal contents was taken through the cannula of each sheep immediately before the morning feeding and strained through 4 layers of cheesecloth. Five milliliters of ruminal fluid was added to $5 \mathrm{~mL}$ of methylgreenformalin solution (Ogimoto and Imai, 1981) and stored at room temperature in the dark until protozoa counting. One milliliter of ruminal fluid was diluted through a series of tubes containing $9.0 \mathrm{~mL}$ of anaerobic dilution solution (Dehority, 1969). Using the $10^{-6}$ through $10^{-11}$ dilution tubes, $1 \mathrm{~mL}$ was placed in each of 3 tubes containing the most probable number media and 24-h ballmilled cellulose (Sigmacell-20, Sigma-Aldrich Chemical SA, Madrid, Spain). Tubes were incubated at $39^{\circ} \mathrm{C}$ for 15 d. Total and cellulolytic bacteria concentrations were determined from the decrease in $\mathrm{pH}$ and by visual loss of cellulose, respectively, according to the most probable number procedure for enumerating bacteria described by Dehority et al. (1989).

The solid digesta was combined with $100 \mathrm{~mL}$ of saline solution $(0.9 \% \mathrm{NaC} 1)$ at $38^{\circ} \mathrm{C}$, mixed gently, and squeezed again to remove residual liquid-associated bacteria $(\mathbf{L A B})$. The procedure was repeated and the solution was added to the ruminal fluid before isolation of LAB by differential centrifugation (Ranilla and Carro, 2003). The solid digesta (100 g) was incubated with saline solution $(0.9 \% \mathrm{NaCl} ; 3 \mathrm{~mL} / \mathrm{g}$ of digesta) containing $0.1 \%$ methylcellulose at $38^{\circ} \mathrm{C}$ for $15 \mathrm{~min}$ in a continuous-shaking water bath ( 65 strokes $/ \mathrm{min})$. Then, $50 \mathrm{~mL}$ of cold $\left(4^{\circ} \mathrm{C}\right)$ saline solution containing $0.1 \%$ methylcellulose was added and the material was stored at $4^{\circ} \mathrm{C}$ for $24 \mathrm{~h}$. The samples were homogenized for $10 \mathrm{~s}$ with a Waring blender (Waring Products Division, New Hartford, CT) and centrifuged at $500 \times g$ for $10 \mathrm{~min}$ at $4^{\circ} \mathrm{C}$, and the supernatant fraction was removed and retained. The solids were resuspended 2 times in saline solution $(0.9 \% \mathrm{NaCl})$ containing $0.1 \%$ methylcellulose and then recentrifuged $\left(500 \times g\right.$ for $10 \mathrm{~min}$ at $\left.4^{\circ} \mathrm{C}\right)$. The final filtrates were then centrifuged at 29,000 $\times$ $g$ for $25 \mathrm{~min}$ at $4^{\circ} \mathrm{C}$ to isolate solid-associated bacteria (SAB). The pellets were washed by resuspension in saline solution, and the centrifugation was repeated. Bacterial pellets were freeze dried and analyzed for bacterial diversity by ARISA.
From d 16 to 25, ruminal digestibility, main fermentation parameters, and microbial protein synthesis were determined. The results are reported in a companion paper (Martínez et al., 2010).

\section{In Vitro Trial}

Two identical 16-d incubation trials were carried out using 8 Rusitec fermenters (Czerkawski and Breckenridge, 1977). Fermenters had an effective volume of $600 \mathrm{~mL}$, and the general incubation procedure was as described by Martínez et al. (2009a). Treatments were assigned randomly so that in each run 2 fermenters received each of the diets. The inoculum was obtained from 8 ruminally fistulated sheep $(59.2 \pm 3.51 \mathrm{~kg}$ of BW). Two sheep received each of the 4 experimental diets for $14 \mathrm{~d}$ before starting the in vitro trial. Each fermenter received daily $30 \mathrm{~g}$ of DM of the corresponding diet (Table 1). Hay was chopped (approximately 0.5$\mathrm{cm}$ pieces), and the concentrate was ground through a 3 -mm sieve. Forage and concentrate were fed via separate nylon bags $(100 \mu \mathrm{m}$ pore; $8 \times 15 \mathrm{~cm})$ and remained in the fermenters for 48 and $24 \mathrm{~h}$, respectively. The flow through fermenters was maintained by continuous infusion of artificial saliva (McDougall, 1948) at a rate of $740 \mathrm{~mL} / \mathrm{d}$ (dilution rate of $5.14 \% / \mathrm{h}$ ).

On d 10,11, 12, 13, and 14, ruminal digestibility, main fermentation parameters, and microbial protein synthesis were determined; the results are reported in a companion paper (Martínez et al., 2010). On d 15 of each period, $5 \mathrm{~mL}$ of ruminal fluid was taken for protozoa counting and $1 \mathrm{~mL}$ of ruminal fluid was used to determine total and cellulolytic bacteria concentrations following the procedures described in the in vivo trial. On d 16, the contents of the 2 nylon bags (1 with forage and 1 with concentrate) collected daily from each fermenter were mixed and used to isolate $\mathrm{SAB}$ as described in the in vivo trial. Approximately $400 \mathrm{~mL}$ of fermenter content was used for isolation of LAB pellets. Isolation of $\mathrm{SAB}$ and $\mathrm{LAB}$ followed the procedures described in the in vivo trial.

\section{Analyses of Bacterial Communities by ARISA}

To analyze the effect of dietary treatments on bacterial communities in $\mathrm{LAB}$ and $\mathrm{SAB}$ isolates, DNA was isolated from bacterial pellets (30 $\mathrm{mg}$ of $\mathrm{DM}$ ) as described by Yu and Morrison (2004). Extracted DNA was amplified using universal bacterial primers $16 \mathrm{~S}-1392 \mathrm{~F}$ and 23S-125R (Danovaro et al., 2006; synthesized by Sigma-Aldrich Quimica SA), which amplify the ITS1 (internal transcribed spacer-1) region in the rRNA operon plus approximately 282 bases of the $16 \mathrm{~S}$ and 23S sRNA. Primer 23S-125R was fluorescently labeled 
Table 1. Bacterial and protozoal numbers in the rumen of sheep and Rusitec fermenters receiving diets differing in forage:concentrate (F:C) ratio and type of forage (FOR)

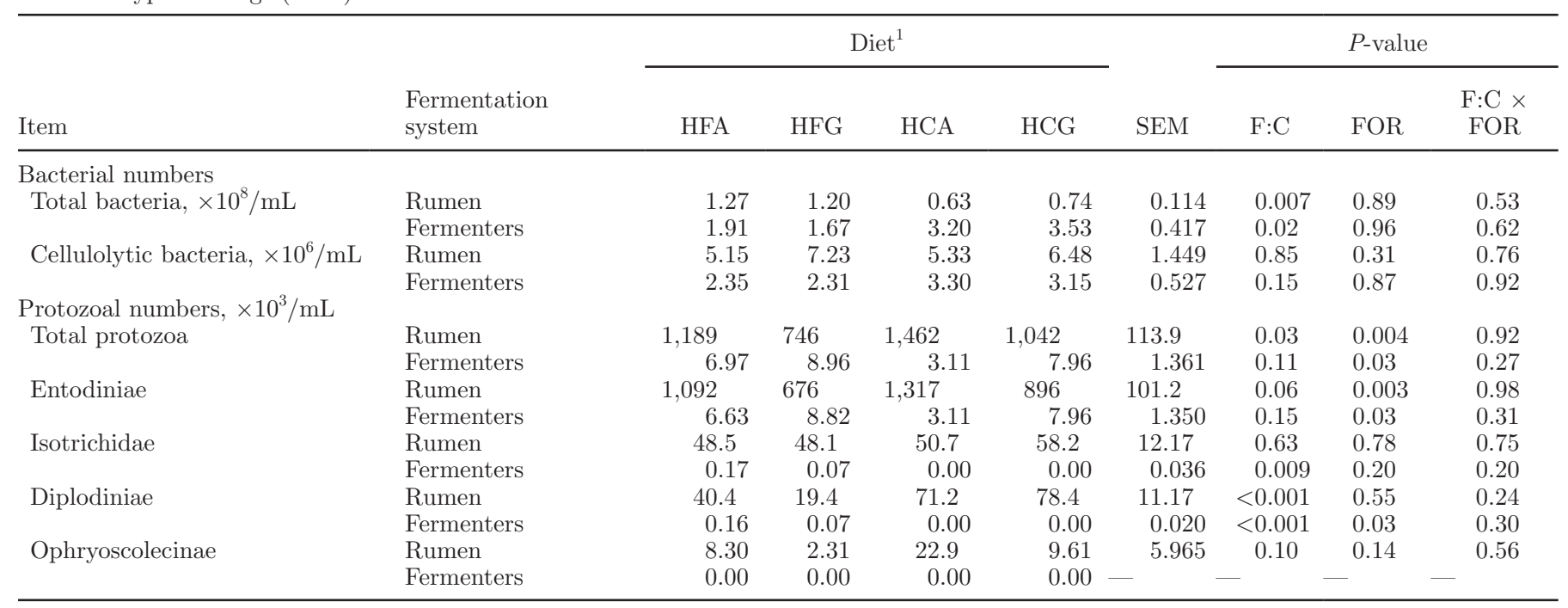

${ }^{1}$ HFA: 70:30 alfalfa hay:concentrate; HFG: 70:30 grass hay:concentrate; HCA: 30:70 alfalfa hay:concentrate; HCG: 30:70 grass hay:concentrate. DM basis.

with the phosphoramidite dye 6-FAM. Each PCR mix (50 $\mu$ L final volume) contained $1 \times$ PCR reaction buffer, $1.5 \mathrm{mM} \mathrm{MgCl}, 0.25 \mu M$ of each primer, each deoxynucleotide triphosphate at a concentration of $0.2 \mathrm{mM}$, and 2.5 U of Taq Polymerase (Biotools B \& M Labs SA, Madrid, Spain). Thermocycling was conducted in a 2720 Thermal Cycler (Applied Biosystem, Foster City, CA) and started with an initial cycle of denaturation $\left(94^{\circ} \mathrm{C}\right.$ for $\left.3 \mathrm{~min}\right)$, followed by 30 cycles of denaturation $\left(94^{\circ} \mathrm{C}\right.$ for $\left.60 \mathrm{~s}\right)$, annealing $\left(55^{\circ} \mathrm{C}\right.$ for $\left.60 \mathrm{~s}\right)$, and elongation $\left(72^{\circ} \mathrm{C}\right.$ for $\left.120 \mathrm{~s}\right)$, ending with a final extension step at $72^{\circ} \mathrm{C}$ for $2 \mathrm{~min}$. The PCR products were analyzed for size and quantity by electrophoresis in $1.5 \%$ agarose gels and further purified using a Qiaquick PCR Purification Kit (Qiagen, Hilden, Germany) according to the manufacturer's protocol. Eluted DNA was quantified fluorimetrically using a Nanodrop ND-1000 (NanoDrop Technologies, Wilmington, DE). For each ARISA, about $5 \mathrm{ng}$ of amplicons was mixed with an internal size standard (GS 1200 LIZ, Applied Biosystems) in deionized formamide, denatured at $94^{\circ} \mathrm{C}$ for $2 \mathrm{~min}$, and immediately chilled on ice. Automated detection of ARISA fragments was carried out using an ABI Prism 3130 Genetic Analyzer (Applied Biosystems) with capillary $(36 \mathrm{~cm} \times$ by $50 \mu \mathrm{m})$ and POP-7 polymer (Applied Biosystems). Peak size and area were estimated by comparison with the internal size standard using the GeneMaker Software (version 1.80, SoftGenetics, State College, PA). To include the maximum number of peaks while excluding background fluorescence, a threshold of 100 fluorescence units was used.
It was considered that the peak profile in ARISA electropherograms reflects the predominant bacterial species or populations present in bacterial pellets, and only the presence or absence of the different peaks was considered for the analysis. The Shannon's diversity index was calculated as described by Shannon and Weaver (1949) per each group of samples (in vivo and in vitro) and was used to evaluate the diversity of bacterial communities. To analyze the similarity between bacteria isolated from the liquid and the solid phase within each system, a percentage similarity index was calculated from the peak profile patterns in the electropherograms of LAB and SAB pellets isolated from each individual (sheep or fermenter) within dietary treatment. Dendrograms were constructed using the Pearson product-moment correlation coefficient and unweighted pair-group method using arithmetic averages options in the MVSP software (version 3.12d, Kovach Computing Service, Anglesey, UK). Principal component analysis (PCA) of all 64 samples was performed using the MVSP software (version 3.12d).

\section{Analytical Procedures}

Ciliate protozoa in preserved rumen fluid samples were counted using a Neubauer Improved Bright-Line counting cell (Hausser Scientific, Horsham, PA). Family Isotrichidae and family Ophryoscolecidae (including subfamilies Entodiniae, Diplodiniae, and Ophryoscolecinae) were identified following descriptions by Dehority (1993) and their numbers were separately recorded. 
Duplicate preparations of each sample were counted; if either value differed from the average by more than $10 \%$, the counts were repeated.

\section{Calculations and Statistical Analyses}

In vivo and in vitro data were analyzed separately to asses the effects of dietary treatments on each fermentation system. Data from in vivo trial were analyzed according to a $4 \times 4$ Latin square model using the MIXED procedure of SAS (SAS Institute Inc., Cary, $\mathrm{NC}$ ) according to the following model:

$$
\mathrm{Y}_{\mathrm{ijkl}}=\mu+\mathrm{c}_{\mathrm{i}}+\mathrm{P}_{\mathrm{j}}+\mathrm{FC}_{\mathrm{k}}+\mathrm{F}_{1}+\mathrm{FCF}_{\mathrm{kl}}+\mathrm{e}_{\mathrm{ijkl}},
$$

where $Y_{i j k l}=$ the dependent variable; $\mu=$ the overall mean; $\mathrm{c}=$ the random effect of sheep $(\mathrm{i}=1$ to 4$) ; \mathrm{P}=$ the fixed effect of period $(\mathrm{j}=1$ to 4$) ; \mathrm{FC}=$ the fixed effect of $\mathrm{F}: \mathrm{C}$ ( $\mathrm{k}=1$ to 2$) ; \mathrm{F}=$ the fixed effect of $\mathrm{FOR}$ $(\mathrm{l}=1$ to 2$) ; \mathrm{FCF}=$ the interaction of $\mathrm{F}: \mathrm{C}$ and $\mathrm{FOR}$; and $\mathrm{e}=$ the residual error. In the analysis of in vitro data the random effect of fermenter was $i=1$ to 8 and the fixed effect of period was $\mathrm{j}=1$ to 2 . When a significant effect of $\mathrm{F}: \mathrm{C} \times$ FOR interaction $(P \leq 0.05)$ was detected, differences among means were tested using Tukey's multiple comparison test.

\section{RESULTS AND DISCUSSION}

The main objective of the present study was to asses the ability of Rusitec fermenters to maintain microbial populations representative of those found in the rumen of sheep fed diets of contrasting quality. Because ruminal microbial populations have been shown to change with time after feeding (Firkins and Yu, 2006), we made an effort to obtain samples at times that were comparable in both fermentation systems. Sheep were fed twice to resemble practical feeding conditions; in contrast, Rusitec fermenters are usually fed only once daily because feeding exposes fermenter contents to oxygen, which is toxic to anaerobic rumen bacteria and inhibits bacterial growth and the adhesion of cellulolytic bacteria to fiber (Roger et al., 1990). Therefore, we decided to take samples of ruminal contents immediately before feeding in fermenters and before the morning feeding in sheep.

\section{Bacterial and Protozoal Numbers}

As shown in Table 1, total bacteria numbers were greater $(P=0.007)$ in the rumen of sheep fed HF diets compared with those fed HC diets, whereas HF fermenters had lower $(P=0.02)$ bacterial concentrations than $\mathrm{HC}$ fermenters. The greater bacteria numbers observed in the $\mathrm{HC}$ fermenters compared with $\mathrm{HF}$ fermenters are in contrast with the lower daily microbial flow observed in $\mathrm{HC}$ fermenters in the same study $(P<0.001$; Martínez et al., 2010). However, it has to be taken into account that total bacterial numbers were determined in the ruminal fluid, and bacteria attached to feed particles can constitute a major proportion of the total bacteria in the rumen. This would also explain why sheep fed HC diets had greater $(P<0.001)$ microbial flows than those fed HF diets (Martínez et al., 2010) but lower total bacteria numbers in the ruminal fluid. The results indicate that Rusitec fermenters did not reproduce the shifts in bacteria numbers induced by changing the $\mathrm{F}: \mathrm{C}$ ratio in the diet of sheep. Moreover, total bacteria numbers were 1.4 and 4.9 times greater in Rusitec than in sheep for $\mathrm{HF}$ and $\mathrm{HC}$ diets, respectively. This is in agreement with Mansfield et al. (1995), who observed that concentrations of viable bacteria were 1.8 times greater in dual-flow continuous-culture fermenters than in the rumen of cows. These authors attributed the observed differences to fermenters defaunation because protozoa moderate ruminal fermentation by reducing bacterial numbers and activity through predation and competition for substrates. In contrast, Muetzel et al. (2009) observed that total bacterial rRNA concentration in single-flow continuous-culture fermenters was significantly lower than in the donor cows, and Gizzi et al. (1998) reported that total bacteria numbers were similar in the rumen of cows and in an improved rumen simulation technique of the batch type operating up to $24 \mathrm{~h}$. Differences among the different types of in vitro systems can help to explain these contrasting results.

The numbers of cellulolytic bacteria were not affected by F:C in sheep $(P=0.85)$ or Rusitec fermenters $(P=0.15)$, which is in agreement with other results (Mackie et al., 1978; Leedle et al., 1986) showing that the number of cellulolytic bacteria, determined by the classical culture-based techniques (Dehority, 1969), remained stable when the concentrate proportion in the diet increased (Mackie et al., 1978; Leedle et al., 1986). Martin et al. (2001) found that the detrimental effect of concentrates on fiber degradation was not attributable to a modification of the balance of the cellulolytic bacteria but rather to a specific decrease in their fibrolytic activity, which is in agreement with our results showing unchanged cellulolytic bacteria numbers. Low $\mathrm{pH}$ values have been shown to decrease the activity, or number, or both, of cellulolytic bacteria, but in our study $\mathrm{pH}$ values did not decrease below 6.0 for HF diets in sheep and fermenters, and $\mathrm{pH}$ values for $\mathrm{HC}$ diets were above 6.0 at most sampling times (results not shown; Martínez et al., 2010). Moreover, the number of cellulolytic bacteria in our study was determined in ruminal fluid, although most cellulolytic bacteria in the rumen are attached to feed particles (Stewart et al., 
1997). In agreement with previous studies (Mansfield et al., 1995; Muetzel et al., 2009), cellulolytic numbers were 2.7 and 1.8 times greater in the rumen than in fermenters for $\mathrm{HF}$ and $\mathrm{HC}$ diets, respectively. Rusitec fermenters are opened once per day to introduce new nylon bags with substrate, thus exposing ruminal microorganisms to oxygen and, therefore, to a substantial stress situation for the strict anaerobics (Gizzi et al., 1998) such as cellulolytic bacteria.

Neither total bacterial nor cellulolytic numbers were affected by FOR in sheep $(P=0.89$ and 0.31 , respectively) or fermenters $(P=0.96$ and 0.87$)$. No $\mathrm{F}: \mathrm{C} \times$ FOR interactions $(P=0.24$ to 0.92$)$ were observed for bacterial and protozoal populations in either sheep rumen or Rusitec, which indicates that changes in microbial populations in response to increasing proportions of concentrate in the diet were not influenced by the basal forage in any system.

Total protozoa numbers were in the range of those previously reported for sheep (Santra et al., 1998; Brossard et al., 2003; Table 1) and Rusitec fermenters fed diets of different quality (Carro et al., 1992, 1995). Total concentration of protozoa in ruminal fluid generally increases with the addition of concentrate to forage diets (Franzolin and Dehority, 1996; Brossard et al., 2003 ), as it was found in our study, in which increasing concentrate from 30 to $70 \%$ augmented $(P=0.03)$ protozoa numbers by 20 and $40 \%$ for A and $\mathrm{G}$ diets, respectively. In contrast, $\mathrm{F}: \mathrm{C}$ ratio had no effect $(P=$ 0.11 ) on total protozoa numbers in fermenters. Sequestration of protozoa among particulate digesta has been identified as an important factor in maintaining protozoa populations in fermenters, and the Rusitec system has a semicontinuous outflow of particles that allows a better retention of protozoa compared with continuousflow fermenters (Nakamura and Kurihara, 1978). A different retention time of solid digesta was used for forage and concentrate (48 and $24 \mathrm{~h}$, respectively) in our study, which implies that retention time for $\mathrm{HC}$ diets was lower than that for HF diets. The negative effects of lower retention times of $\mathrm{HC}$ diets on protozoal populations probably counteracted the positive effects produced by feeding concentrates, and this may have contributed to the lack of differences between HF and $\mathrm{HC}$ fermenters in protozoa numbers. In agreement with this hypothesis, Crawford et al. (1980) observed that continuous-flow fermenters with a solid digesta retention time of $29.7 \mathrm{~h}$ maintained relatively stable levels of $1.0 \times 10^{4}$ protozoa $/ \mathrm{mL}$, but decreasing solids retention time to 22.0 and $14.3 \mathrm{~h}$ reduced protozoa numbers by 100 and 250 times, respectively.

In agreement with the literature (Santra et al., 1998; Dehority, 2003), Entodiniae represented 86 and $92 \%$ of total protozoa in sheep fed $\mathrm{HF}$ and $\mathrm{HC}$ diets, respec- tively. Entodiniae were also the most abundant protozoa in Rusitec fermenters, representing 97 and 100\% of total protozoa for $\mathrm{HF}$ and $\mathrm{HC}$ diets, respectively, which is in accordance with other studies (Slyter and Putnam, 1967; Carro et al., 1992, 1995). In general, a reduction in Isotrichidae, Diplodiniae, and Ophryoscolecinae numbers has been reported by feeding $\mathrm{HC}$ diets to ruminants because of the low ruminal $\mathrm{pH}$ values produced by the rapid fermentation of nonstructural carbohydrates (Franzolin and Dehority, 1996; Hristov et al., 2001). In our study, Isotrichidae protozoa were not affected by $\mathrm{F}$ :C ratio $(P=0.63)$, but Diplodiniae numbers were greater $(P<0.001)$ and Ophryoscolecinae numbers tended to be greater $(P=0.10)$ in sheep fed $\mathrm{HC}$ diets than in those fed HF diets, which may have been attributable to the relatively high $\mathrm{pH}$ values observed in HC-fed sheep in our study (mean values over the 12 -h postfeeding period were 6.47 and 6.19 for $\mathrm{HF}$ and $\mathrm{HC}$ diets, respectively; Martínez et al., 2010). The results indicate that feeding up to $70 \%$ of concentrate did not have any detrimental effect on any of the protozoa groups identified in our study in sheep. In contrast, Isotrichidae and Diplodiniae disappeared completely in the fermenters fed HC diets, although they were maintained in the fermenters fed HF diets. The complete disappearance of Isotrichidae in HC-fed fermenters may be $\mathrm{pH}$ related. Eadie (1962) found that Isotrichidae did not develop in the rumen of calves and sheep at $\mathrm{pH}$ below 6.5. Whereas values did not decrease below 6.44 and 6.11 in fermenters fed HFA and HFG, respectively, minimum values were 5.76 and 5.74 in fermenters fed HCA and HCG, respectively (results not shown; Martínez et al., 2010). In agreement with this hypothesis, Carro et al. (1995) found that Isotrichidae represented $12.2 \%$ of total protozoa in Rusitec fermenters maintained at $\mathrm{pH} 6.86$, but they completely disappeared when the $\mathrm{pH}$ decreased to 6.17 by changing the composition of the artificial saliva infused into the system.

The disappearance of Ophryoscolecinae from all fermenters may be partially explained by their long generation time and large size. Retention time of solid digesta in fermenters was 24 and $48 \mathrm{~h}$ for concentrate and forage, respectively, which is shorter than the generation times of up to $3 \mathrm{~d}$ observed for Ophryoscolecinae (Sylvester et al., 2009). Ophryoscolecinae are one of the largest ruminal protozoa and can measure up to 200 $\mu \mathrm{m}$ in length (Williams et al., 1961). The pore size of nylon bags $(100 \mu \mathrm{m})$ used in Rusitec fermenters may have limited the entrance of Ophryoscolecinae into the bags and their attachment to digesta.

Both total protozoa and Entodiniae numbers were greater $(P=0.004$ and 0.003 , respectively) in sheep fed A diets than in those fed $\mathrm{G}$ diets. In contrast, ferment- 
ers fed A diets had lower total protozoa and Entodiniae numbers $(P=0.03)$ than fermenters fed $\mathrm{G}$ diets. These results seem to indicate that protozoa were retained more successfully in the unfermentable residues of $G$ than in those of $\mathrm{A}$, as has been previously observed by Abe and Kurihara (1984). The type of forage in the diet did not affect ( $P=0.14$ to 0.78) Isotrichidae, Diplodini$a e$, or Ophryoscolecinae numbers in sheep, but numbers of Diplodiniae were greater $(P=0.03)$ in fermenters fed A diets compared with fermenters fed $G$ diets.

Results indicate that under conditions of this study, protozoa population in Rusitec fermenters was not representative of that found in the rumen of sheep fed the same diets. In addition, protozoa numbers in fermenters were 121 and 226 times lower than those in the sheep rumen for $\mathrm{HF}$ and $\mathrm{HC}$ diets, respectively, confirming previous observations (Mansfield et al., 1995; Muetzel et al., 2009). The lower numbers and diversity of protozoa in fermenters may have played a role in several of the discrepancies in fermentation parameters between the rumen and fermenters observed previously (Martínez et al., 2010).

\section{Bacterial Diversity}

The approach used in this study for assessing bacterial diversity differs from others that have compared microbial populations in the rumen with those in fermenters. Differences in chemical composition between $\mathrm{LAB}$ and $\mathrm{SAB}$ are widely demonstrated in both the rumen (Merry and McAllan, 1983; Ipharraguerre et al., 2007) and fermenters (Carro and Miller, 2002; MolinaAlcaide et al., 2009), and there is a general agreement that SAB should be taken into account in determining microbial protein synthesis in vivo and in vitro. Because both bacterial fractions are usually isolated in studies measuring microbial growth in the rumen, we decided to analyze the bacterial diversity in both types of pellets. Whereas LAB are easy to isolate, SAB have to be detached from feed particles, and to date there is no consensus on the ideal method to obtain a representative SAB isolate. In studies conducted in our laboratory in sheep (Ramos et al., 2009) and Rusitec fermenters (Martínez et al., 2009b) 3 methods to detach SAB from solid ruminal digesta were compared, and the results showed that the treatment of solid digesta with a solution of methylcellulose was the one that produced $\mathrm{SAB}$ pellets with the greatest similarity to the bacterial communities attached to the digesta; this procedure was therefore used to isolate $\mathrm{SAB}$ from ruminal digesta in both systems.

In the Rusitec system, LAB are separated from SAB, which are attached to feed enclosed in the nylon bags. An exchange between these bacterial fractions is made possible by the continuous perfusion of the solid by the liquid and by returning the washings from the removed bags to the fermenter. These washings contain a relatively large proportion of loosely attached microorganisms (Czerkawski and Breckenridge, 1977), which are returned to the liquid phase and isolated as LAB. Because it has been shown that processing method of ruminal digesta before DNA extraction has a profound effect on diversity results (Firkins and Yu, 2006), solid digesta from sheep rumen was washed twice with saline solution and the solution was added to the ruminal fluid before isolation of LAB to resemble the operation procedure used in the fermenters.

Several molecular techniques can be used to analyze the diversity of rumen microbial populations, and all of them have assumptions or limitations that must be considered relative to their advantages (Firkins and $\mathrm{Yu}$, 2006). The ARISA technique analysis was selected for the study because it is a rapid and effective method for assessing microbial community diversity (Fisher and Triplett, 1999) and it allows a fast analysis of a large number of samples. Although ARISA cannot provide specific taxonomic identification of individual peaks detected in the electropherograms, it is considered to be more sensitive than other fingerprinting methods, such as DGGE or SSCP (Danovaro et al., 2006), and to be well suited to detect subtle changes in ruminal bacterial community composition (Welkie et al., 2010). The ARISA approach has been recently used to monitor shifts in ruminal bacteria (Welkie et al., 2010) and fungi (Denman et al., 2008) and to analyze the representativeness of SAB pellets isolated from ruminal digesta (Ramos et al., 2009).

A total of 170 peaks were detected in the ARISA electropherograms of bacterial pellets across the full set of 64 samples, from which 160 were detected in at least 1 individual from each system (sheep or fermenter). The number of peaks in bacterial pellets isolated from sheep rumen ranged from 42 to 82 for LAB and from 31 to 81 for SAB, with a total of 168 peaks. In Rusitec fermenters, the number of peaks ranged from 53 to 79 for LAB and from 21 to 69 for SAB, with 162 peaks in total. In the bacterial pellets from sheep, there were 8 peaks found only in LAB (4.8\% of detected) and 6 appeared only in SAB (3.6\% of detected). In a study using ARISA to analyze the ruminal bacterial community in 2 lactating cows fed a $65 \%$ forage diet, Welkie et al. (2010) observed that $13.5 \%$ of the peaks were detected only in the liquid phase and $1.9 \%$ were detected only in the solid phase. In the Rusitec system, 30 peaks $(18.5 \%$ of detected) were found only in LAB and $8(4.9 \%)$ were unique to SAB.

Kocherginskaya et al. (2001) hypothesized a priori that ruminal bacteria diversity would be greater for HF 
Table 2. Values of Shannon index and numbers of peaks detected in the automated ribosomal intergenic spacer analysis (ARISA) electropherograms of liquid-associated (LAB) and solid-associated (SAB) bacterial pellets isolated from the rumen of sheep and Rusitec fermenters receiving diets differing in forage:concentrate $(\mathrm{F}: \mathrm{C})$ ratio and type of forage (FOR), and similarity index of ARISA profiles between LAB and SAB pellets

\begin{tabular}{|c|c|c|c|c|c|c|c|c|c|}
\hline Item & $\begin{array}{l}\text { Fermentation } \\
\text { system }\end{array}$ & \multicolumn{4}{|c|}{$\operatorname{Diet}^{1}$} & SEM & \multicolumn{3}{|c|}{$P$-value } \\
\hline LAB & Fermenters & 58.3 & 73.0 & 61.8 & 70.5 & 1.76 & 0.83 & 0.005 & 0.46 \\
\hline \multirow[t]{2}{*}{ SAB } & Rumen & 54.5 & 77.5 & 48.5 & 63.0 & 3.57 & 0.03 & 0.002 & 0.28 \\
\hline & Fermenters & 27.8 & 64.5 & 34.3 & 63.8 & 3.17 & 0.41 & $<0.001$ & 0.32 \\
\hline LAB & Fermenters & 4.05 & 4.26 & 4.12 & 4.25 & 0.022 & 0.29 & 0.004 & 0.83 \\
\hline \multirow[t]{2}{*}{$\mathrm{SAB}$} & Rumen & 3.95 & 4.34 & 3.88 & 4.12 & 0.071 & 0.05 & 0.004 & 0.29 \\
\hline & Fermenters & 3.28 & 4.17 & 3.44 & 4.15 & 0.093 & 0.50 & 0.001 & 0.41 \\
\hline \multirow[t]{2}{*}{ Similarity index, \% } & Rumen & 56.5 & 50.7 & 51.7 & 54.1 & 5.46 & 0.90 & 0.76 & 0.48 \\
\hline & Fermenters & 49.3 & 78.1 & 53.2 & 80.4 & 3.43 & 0.39 & $<0.001$ & 0.82 \\
\hline
\end{tabular}

${ }^{1}$ HFA: 70:30 alfalfa hay:concentrate; HFG: 70:30 grass hay:concentrate; HCA: 30:70 alfalfa hay:concentrate; HCG: 30:70 grass hay:concentrate. DM basis.

than for mixed grain-forage diets, although subsequent diversity index did not support this hypothesis in their study, and corn-fed steers displayed more diverse and rich bacterial populations than hay-fed steers. In our study (Table 2), no effect of $\mathrm{F}$ : $\mathrm{C}$ ratio was detected in either the number of peaks or the Shannon index in LAB isolated from sheep $(P=0.39$ and 0.23 , respectively) or fermenters $(P=0.83$ and 0.29$)$. In contrast, the number of peaks and the Shannon index were greater in $\mathrm{SAB}$ isolated from sheep fed HF diets than from those fed HC diets $(P=0.03$ and 0.05 , respectively), although no effect of $\mathrm{F}: \mathrm{C}$ ratio was detected in $\mathrm{SAB}$ isolated from fermenters $(P=0.41$ and 0.50$)$. The greater diversity in SAB from sheep fed HF diets is in accordance with the results of Larue et al. (2005), who observed that bacterial diversity tended to be greater in sheep fed only orchardgrass hay compared with those fed a diet of orchardgrass and concentrate (70:30).

The SAB isolated from sheep and fermenters fed G diets had greater numbers of peaks and Shannon index values than those isolated when A diets were fed $(P<$ 0.001 to 0.004). Greater numbers of peaks and Shannon index for $\mathrm{G}$ diets compared with $\mathrm{A}$ diets were also observed for LAB pellets in fermenters $(P=0.005$ and $0.004)$, but no effect $(P=0.65$ and 0.54$)$ of FOR on LAB profile was found in sheep. No $(P=0.41$ to 0.82$)$ $\mathrm{F}: \mathrm{C} \times \mathrm{FOR}$ interaction was observed for any variable. The results indicate that bacterial diversity in the rumen was more markedly affected by FOR than by F:C ratio in the diet. This is in agreement with the results of Koike et al. (2003), who observed that the set of bacteria isolated from orchardgrass seemed to be different from the set isolated from alfalfa when samples of both forages were incubated in sacco in the rumen of sheep and bacterial $16 \mathrm{~S}$ rDNA were cloned. These authors concluded that the hay source may affect the members of fiber-associated rumen bacterial community, which is in agreement with our results.

In paired $t$-tests within each fermentation system (in vivo or in vitro), there was no difference between LAB and SAB from sheep in either the number of peaks $(P=0.74 ; 62.6$ vs. 60.9$)$ or the Shannon index $(P=$ $0.89 ; 4.11$ vs. 4.07$)$. In contrast, in Rusitec fermenters LAB had greater number of peaks $(P<0.001 ; 65.9$ vs. 47.6) and values of Shannon index $(P=0.001 ; 4.17$ vs. 3.76) compared with $\mathrm{SAB}$, indicating a greater bacterial diversity in the bacterial pellets isolated from the liquid phase compared with those isolated from the solid digesta. It must be noticed that whereas LAB are relatively easy to isolate and a great recovery of the bacteria populations should be expected, recovery of SAB from ruminal digesta is usually lower than $50 \%$, indicating that a pure $\mathrm{SAB}$ isolate may not be representative of the total SAB population (Ramos et al., 2009). In previous studies conducted at our laboratory, the treatment of ruminal digesta from Rusitec fermenters with the methylcellulose solution used in the present work resulted in the recovery of 58.9 and $44.8 \%$ of total SAB for forage and concentrate, respectively (Martínez et al., 2009b), whereas SAB recovery from ruminal digesta from sheep was only 36.7 and 29.3 for $\mathrm{HF}$ and HC diets, respectively (Ramos et al., 2009). In addition, the similarity index between the bacterial communities in the solid digesta and those in SAB pellets was greater in Rusitec fermenters $(84.0 \%$ for forage vs. $86.4 \%$ for concentrate) compared with sheep (52.2 and $56 \%$ for $\mathrm{HF}$ and $\mathrm{HC}$ diets, respectively). These data indicate that recovery and representativeness of SAB from sheep digesta are lower compared with Rusitec fermenters. 
$\mathrm{LAB}$
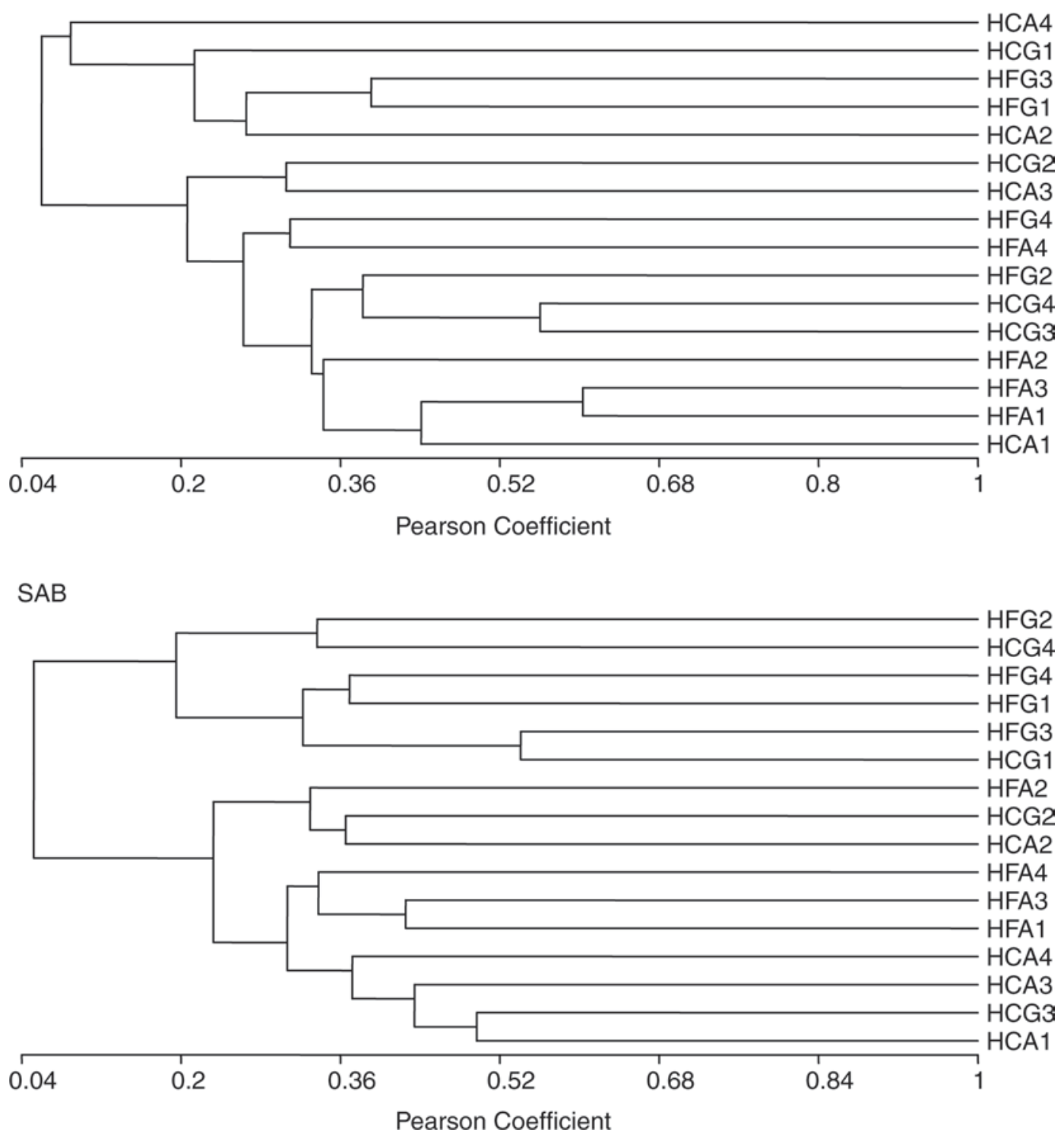

Figure 1. Dendrograms of automated ribosomal intergenic spacer analysis profiles of liquid-associated (LAB) and solid-associated (SAB) bacterial communities in sheep receiving diets with forage:concentrate ratios of 70:30 (high forage; HF) or 30:70 (high concentrate; HC) and alfalfa hay (A) or grass hay $(\mathrm{G})$ as forage. Numbers 1 to 4 correspond to individual sheep.

There was a significant relationship $(\mathrm{r}=0.734 ; P=$ $0.001 ; \mathrm{n}=16$ ) between the number of peaks in LAB and that in $\mathrm{SAB}$ in Rusitec fermenters, but no relationship was found in vivo $(\mathrm{r}=0.098 ; P=0.72 ; \mathrm{n}=16$; results not shown). This would indicate that the effects of diet characteristics on bacterial diversity were similar in $\mathrm{LAB}$ and $\mathrm{SAB}$ communities in fermenters but contrasting in sheep. In fermenters, feeding $\mathrm{G}$ diets promoted a greater diversity of both $\mathrm{LAB}$ and $\mathrm{SAB}$ compared with feeding $\mathrm{A}$ diets, and $\mathrm{F}: \mathrm{C}$ ratio had no effect on $\mathrm{LAB}$ or SAB diversity. In sheep, LAB diversity was unaffected by diet, but diversity of $\mathrm{SAB}$ was greater for $\mathrm{G}$ diets compared with A diets and for $\mathrm{HC}$ diets compared with HF diets.

Larue et al. (2005) and Michalet-Doreau et al. (2001) in sheep, and Boguhn et al. (2008) in Rusitec fermenters, reported differences in the bacterial communities found in the fluid and those in the solid phase of the rumen. In our study, similarity index between LAB and SAB ranged from 37.8 to $74.3 \%$ in sheep and from 41.0 to $81.1 \%$ in fermenters. Diet characteristics did not affect $(P=0.90$ and 0.76 for $\mathrm{F}: \mathrm{C}$ and FOR, respectively) similarity indexes between $\mathrm{LAB}$ and $\mathrm{SAB}$ in sheep (Table 2 ), but similarity between the 2 bacterial frac- 

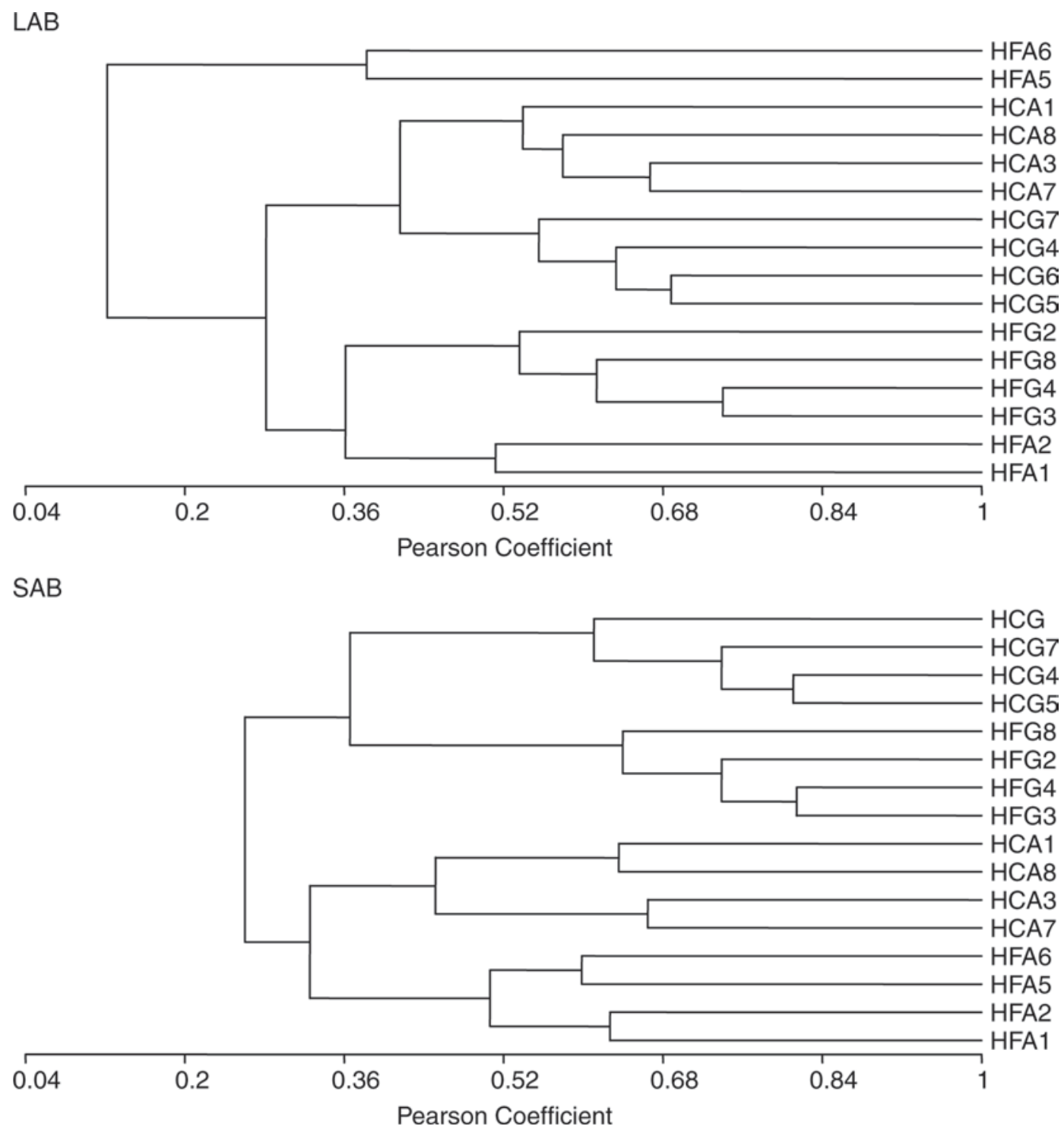

Figure 2. Dendrograms of automated ribosomal intergenic spacer analysis profiles of liquid-associated (LAB) and solid-associated (SAB) bacterial communities in sheep and Rusitec fermenters receiving diets with forage:concentrate ratios of 70:30 (high forage; HF) or 30:70 (high concentrate; $\mathrm{HC}$ ) and alfalfa hay (A) or grass hay $(\mathrm{G})$ as forage. Numbers 1 to 8 correspond to individual fermenters.

tions was greater in fermenters fed $\mathrm{G}$ diets compared with those fed A diets (79.3 vs. $51.3 \%)$. Similarity indices between $\mathrm{LAB}$ and $\mathrm{SAB}$ were greater in fermenters than in sheep $(P=0.001 ; 65.3$ vs. $53.3 \%$, mean values averaged across diets), although a system $\times$ FOR interaction was observed $(P<0.001)$.

Several studies have pointed out large variations of microbial communities between animals (Mackie et al., 1999; Firkins and $\mathrm{Yu}, 2006$ ). To reduce the interanimal variability in our study, we decided to use a $4 \times 4$ Latin square design in the in vivo trial. Significant effects of sheep were found on the numbers of peaks and Shannon index of LAB ( $P=0.008$ and 0.005 , respectively) and $\operatorname{SAB}(P=0.02$ and 0.02 , respectively), confirming previous observations. In contrast, no effect $(P=0.11$ to 0.26 ) of fermenter was detected on the number of peaks or Shannon index in LAB and SAB. Microbial communities in the gastrointestinal tract are influenced by numerous external and internal host-related factors (Mackie et al., 1999). The host animal influences microbial population in the rumen through physiological processes (mastication, rumination, feeding behavior, digesta passage rate, and so on) that cannot appropriately be mimicked in vitro. In the Rusitec system, operating parameters (input and buffer capacity of artificial saliva, feeding rate, movements, and so on) 


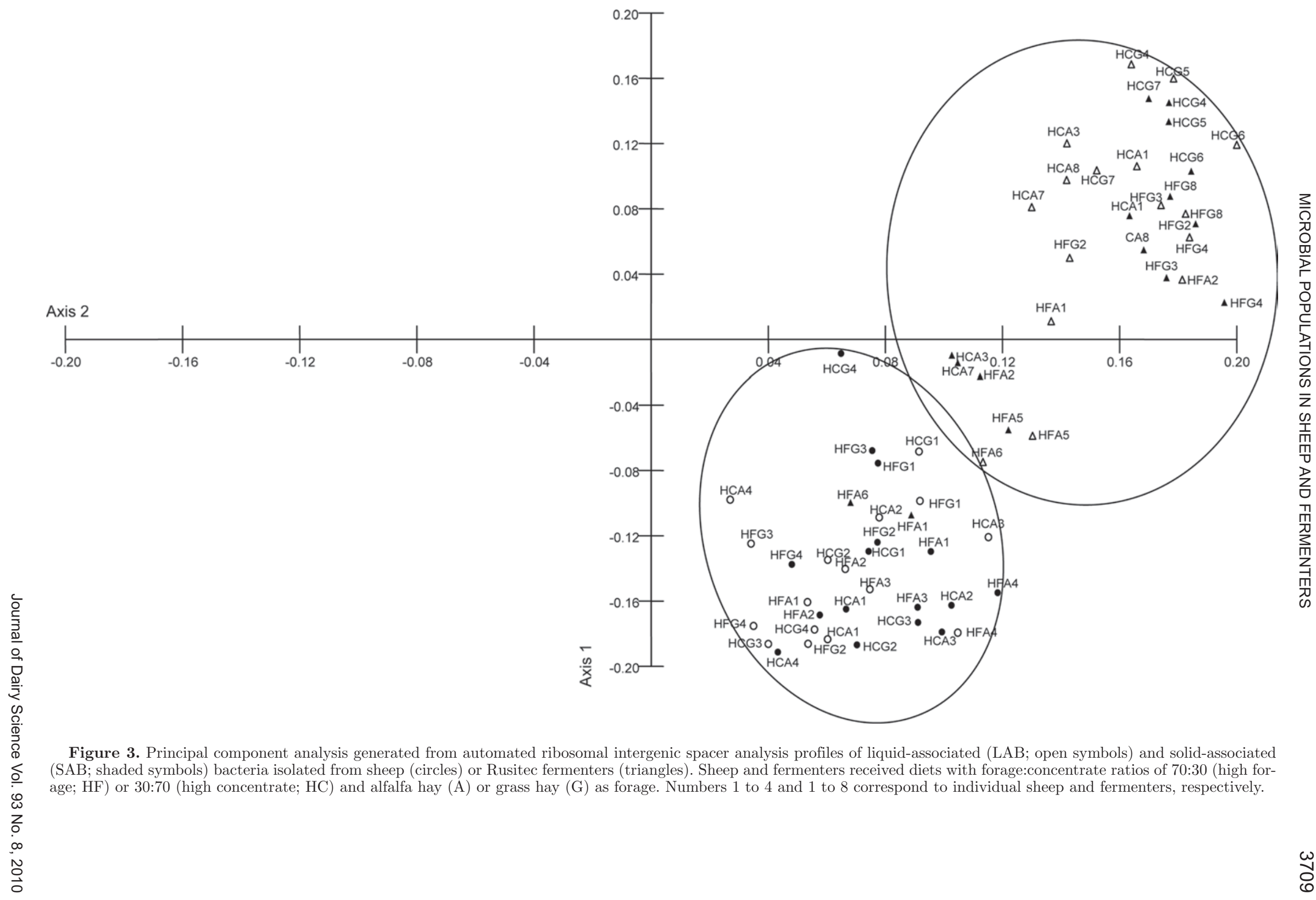


are identical in all fermenters; therefore, the lack of significant fermenter effects seems to be logical.

Figures 1 and 2 show the dendrograms of the ARISA profiles of $\mathrm{LAB}$ and $\mathrm{SAB}$ bacterial communities in sheep and Rusitec fermenters, respectively. A different clustering pattern was observed in the 2 systems and in the 2 bacterial fractions. For LAB pellets isolated from sheep rumen, no clear clustering pattern could be established based on F:C ratio or FOR. The $\mathrm{SAB}$ pellets formed 2 major clusters according to FOR, with most pellets from sheep fed A diets clustered together and the majority of pellets from the sheep fed G diets grouped in a different cluster.

In Rusitec fermenters, LAB pellets clustered first according to $\mathrm{F}$ : $\mathrm{C}$ ratio and, within $\mathrm{HF}$ or $\mathrm{HC}$ diets, according to the type of forage. The SAB pellets followed a grouping trend similar to that observed in vivo, with all pellets from fermenters fed A diets clustered together and those from fermenters fed $\mathrm{G}$ diets forming a different cluster. Two clear subclusters according to $\mathrm{F}$ :C ratio were observed within each of the 2 main clusters. The results indicate that in both systems $\mathrm{SAB}$ communities were mainly affected by FOR, whereas the structure of LAB communities depended primarily on $\mathrm{F}: \mathrm{C}$ ratio in Rusitec fermenters and seemed to be less dependent on the diet in sheep.

These results suggest a different structure of the bacterial communities found in the rumen of sheep and in the Rusitec fermenters, which was confirmed by analyzing all samples together by PCA (Figure 3) and clustering analysis (results not shown). Two distinct clusters for in vivo and in vitro samples were observed in the clustering analysis. In the PCA, about $33 \%$ of the variance between samples was explained by the 2 main components (24.4\% on $\mathrm{C} 1$ and $8.8 \%$ on $\mathrm{C} 2$ ), giving an indication of the multiple factors that affect ruminal bacterial community structure. The PCA clearly discriminated between Rusitec and in vivo profiles, and all in vivo samples grouped together whereas most samples from fermenters formed a distinct group. Within systems, there was not a clear separation between LAB and $\mathrm{SAB}$ samples obtained from the rumen of sheep, but in the Rusitec system LAB and SAB isolated from fermenters fed $\mathrm{G}$ diets tended to be close to each other, confirming the higher similarity between these 2 bacterial fractions for $\mathrm{G}$ diets compared with A diets (Table 2).

\section{CONCLUSIONS}

The results of this study confirmed previous observations that Rusitec fermenters do not maintain protozoa numbers at in vivo levels and showed that diversity of protozoa population was not fully representative of that in the rumen of sheep fed the same diets. Cellulolytic numbers were greater in sheep compared with fermenters for all diets, which may be related to operating conditions in Rusitec system and low protozoal populations. Sheep and fermenters showed relatively similar total bacterial numbers with HF diets, but numbers in fermenters were about 4.9 times greater than in sheep when $\mathrm{HC}$ diets were fed. Bacterial diversity in SAB pellets was mainly affected by the type of forage in sheep and fermenters, but the structure of LAB communities depended primarily on $\mathrm{F}: \mathrm{C}$ ratio in Rusitec fermenters and seemed to be independent of the diet in sheep. The different conditions in the fermenters compared with the sheep rumen might have caused a selection of some bacterial strains. Studies identifying the changes in bacterial communities through the incubation period in Rusitec fermenters fed diets of different composition would be helpful to understand the observed differences between in vivo and in vitro systems.

\section{REFERENCES}

Abe, M., and Y. Kurihara. 1984. Long-term cultivation of certain rumen protozoa in a continuous fermentation system supplemented with sponge materials. J. Appl. Bacteriol. 56:201-203.

Boguhn, J., E. Strobel, M. Witziga, C. C. Tebbec, and M. Rodehutscord. 2008. Description of the structural diversity of rumen microbial communities in vitro using single-strand conformation polymorphism profiles. Arch. Anim. Nutr. 62:454-467.

Brossard, L., C. Martin, and B. Michalet-Doreau. 2003. Ruminal fermentative parameters and blood acid-basic balance changes during the onset and recovery of induced latent acidosis in sheep. Anim. Res. 52:513-530.

Carro, M. D., P. Lebzien, and K. Rohr. 1992. Influence of yeast culture on the in vitro fermentation (Rusitec) of diets containing variable portions of concentrates. Anim. Feed Sci. Technol. 37:209-220.

Carro, M. D., P. Lebzien, and K. Rohr. 1995. Effects of pore size of nylon bags and dilution rate parameters in a semi-continuous artificial rumen. Small Rumin. Res. 15:113-119.

Carro, M. D., and E. L. Miller. 2002. Comparison of microbial markers $\left({ }^{15} \mathrm{~N}\right.$ and purine bases) and bacterial isolates for the estimation of rumen microbial protein synthesis. Anim. Sci. 75:315-321.

Crawford, R. J. Jr., W. H. Hoover, and P. H. Knowlton. 1980. Effects of solids and liquid flows on fermentation in continuous cultures. I. Dry matter and fiber digestion, VFA production and protozoa numbers. J. Anim. Sci. 51:975-985.

Czerkawski, J. W., and G. Breckenridge. 1977. Design and development of a long-term rumen simulation technique (Rusitec). Br. J. Nutr. 38:371-384.

Danovaro, R., G. M. Luna, A. Dell'Anno, and B. Pietrangeli. 2006. Comparison of two fingerprinting techniques, terminal restriction fragment length polymorphism and automated ribosomal intergenic spacer analysis, for determination of bacterial diversity in aquatic environments. Appl. Environ. Microbiol. 72:5982-5989.

Dehority, B. A. 1969. Pectin-fermenting bacteria isolated from the bovine rumen. J. Bacteriol. 99:189-196.

Dehority, B. A. 1993. Laboratory Manual for Classification and Morphology of Ruminal Ciliate Protozoa. CRC Press, Boca Raton, FL.

Dehority, B. A. 2003. Rumen Microbiology. Nottingham Univ. Press, Nottingham, UK.

Dehority, B. A., P. A. Tirabasso, and A. P. Grifo Jr.. 1989. Mostprobable-number procedures for enumerating ruminal bacteria, including the simultaneous estimation of total bacteria and 
cellulolytic numbers in one medium. Appl. Environ. Microbiol. 55:2789-2792.

Denman, S. E., M. J. Nicholson, J. L. Brookman, M. K. Theodorou, and C. S. McSweeney. 2008. Detection and monitoring of anaerobic rumen fungi using an ARISA method. Lett. Appl. Microbiol. 47:492-499.

Eadie, J. M. 1962. The development of rumen microbial populations in lambs and calves under various conditions of management. J. Gen. Microbiol. 29:563-578.

Firkins, J. L., and Z. Yu. 2006. Characterisation and quantification of the microbial populations of the rumen. Pages 19-54 in Ruminant, Digestion, Metabolism and Impact on Nutrition on Gene Expression, Immunology and Stress. K. Serjsen, T. Hevelplund, and M.O. Nielsen, ed. Wageningen Academic Publishers, Wageningen, the Netherlands.

Fisher, M. M., and E. W. Triplett. 1999. Automated approach for ribosomal intergenic spacer analysis of microbial diversity and its application to freshwater bacterial communities. Appl. Environ. Microbiol. 65:4630-4636.

Franzolin, R., and B. A. Dehority. 1996. Effect of prolonged highconcentrate feeding on ruminal protozoa concentrations. J. Anim. Sci. 74:2803-2809.

Gizzi, G., R. Zanchi, and F. Sciaraffia. 1998. Comparison of microbiological and fermentation parameters obtained with an improved rumen in vitro technique with those obtained in vivo. Anim. Feed Sci. Technol. 73:291-305.

Hristov, A. N., M. Ivan, L. M. Rode, and T. A. McAllister. 2001. Fermentation characteristics and ruminal ciliate protozoal populations in cattle fed medium- or high-concentrate barleybased diets. J. Anim. Sci. 79:515-524.

Ipharraguerre, I. R., S. M. Reynal, M. Liñeiro, G. A. Broderick, and J. H. Clark. 2007. A comparison of sampling sites, digesta and microbial markers, and microbial references for assessing the postruminal supply of nutrients in dairy cows. J. Dairy Sci. 90:1904-1919.

Kocherginskaya, S. A., R. I. Aminov, and B. A. White. 2001. Analysis of the rumen bacterial diversity under two different diet conditions using denaturing gradient gel electrophoresis, random sequencing, and statistical ecology approaches. Anaerobe 7:119-134.

Koike, S., J. Pan, Y. Kobayashi, and K. Tanaka. 2003. Kinetics of in sacco fiber attachment of representative ruminal cellulolytic bacteria monitored by competitive PCR. J. Dairy Sci. 86:1429 1435.

Larue, R., Z. Yu, V. A. Parisi, A. R. Egan, and M. Morrison. 2005. Novel microbial diversity adherent to plant biomass in the herbivore gastrointestinal tract, as revealed by ribosomal intergenic spacer analysis and rrs gene sequencing. Environ. Microbiol. 74:530543.

Leedle, J. A. Z., K. Barshun, and R. B. Hespell. 1986. Postprandial trends in estimated ruminal digesta polysaccharides and their relation to changes in bacterial groups and ruminal fluid characteristics . J. Anim. Sci. 62:789-803.

Mackie, R. I., F. M. C. Gilchrist, A. M. Roberts, P. E. Hannah, and H. M. Schwartz. 1978. Microbiological and chemical changes in the rumen during the stepwise adaptation of sheep to high concentrate diets. J. Agric. Sci. 90:241-254.

Mackie, R. I., A. Sghir, and H. R. Gaskins. 1999. Developmental microbial ecology of the neonatal gastrointestinal tract. Am. J. Clin. Nutr. 69:1035S-1045S.

Mansfield, H. R., M. I. Endres, and M. D. Stern. 1995. Comparison of microbial fermentation in the rumen of dairy cows and dual flow continuous culture. Anim. Feed Sci. Technol. 55:47-66.

Martin, C., L. Millet, G. Fonty, and B. Michalet-Doreau. 2001. Cereal supplementation modified the fibrolytic activity but not the structure of the cellulolytic bacterial community associated with rumen solid digesta. Reprod. Nutr. Dev. 41:413-424.

Martínez, M. E., M. J. Ranilla, S. Ramos, M. L. Tejido, and M. D. Carro. 2009a. Effects of dilution rate and retention time of concentrate on efficiency of microbial growth, methane production, and ruminal fermentation in Rusitec fermenters. J. Dairy Sci. 92:3930-3938.
Martínez, M. E., M. J. Ranilla, S. Ramos, M. L. Tejido, C. Saro, and M. D. Carro. 2009b. Evaluation of procedures for detaching particleassociated microbes from forage and concentrate incubated in Rusitec fermenters: Efficiency of recovery and representativeness of microbial isolates. J. Anim. Sci. 87:2064-2072.

Martínez, M. E., M. J. Ranilla, M. L. Tejido, C. Saro, and M. D. Carro. 2010. Comparison of fermentation of diets of variable composition in the rumen of sheep and Rusitec fermenters. I. Digestibility, fermentation parameters, and efficiency of microbial protein synthesis. J. Dairy Sci. 93:3684-3698.

McDougall, E. I. 1948. Studies on ruminant saliva. I. The composition and output of sheep's saliva. Biochem. J. 43:99-109.

Merry, R. J., and A. B. McAllan. 1983. A comparison of the chemical composition of mixed bacteria harvested from the liquid and solid fractions of rumen digesta. Br. J. Nutr. 50:701-709.

Michalet-Doreau, B., I. Fernandez, C. Peyron, L. Millet, and G. Fonty 2001. Fibrolytic activities and cellulolytic bacterial community structure in the solid and liquid phases of rumen contents. Reprod. Nutr. Dev. 41:187-194.

Molina-Alcaide, E. A. Moumen, I. Martín García, and M. D. Carro. 2009. Comparison of bacterial pellets and microbial markers for the estimation of the microbial nitrogen and amino acids flows from single flow continuous culture fermenters fed diets containing two-stage olive cake. J. Anim. Physiol. Anim. Nutr. (Berl.) 93:527-537.

Muetzel, S., P. Lawrence, E. M. Hoffmann, and K. Becker. 2009. Evaluation of a stratified continuous rumen incubation system. Anim. Feed Sci. Technol. 151:32-43.

Nakamura, F., and Y. Kurihara. 1978. Maintenance of a certain rumen protozoal population in a continuous in vitro fermentation system. Appl. Environ. Microbiol. 35:500-506.

NRC. 1985. Nutrient Requirements of Sheep. 6th ed. National Academy Press, Washington, DC

Ogimoto, K., and S. Imai. 1981. Atlas of Rumen Microbiology. Scientific Societies Press, Tokyo, Japan.

Prevot, S., J. Senaud, and G. Prensier. 1994. Variation in the composition of the ruminal bacterial microflora during the adaptation phase in an artificial fermenter (Rusitec). Zoolog. Sci. 11:871-882.

Ramos, S., M. L. Tejido, M. J. Ranilla, M. E. Martínez, C. Saro, and M. D. Carro. 2009. Influence of detachment procedure and diet on recovery of solid-associated bacteria from sheep ruminal digesta and representativeness of bacterial isolates as assessed by automated ribosomal intergenic spacer analysis-polymerase chain reaction. J. Dairy Sci. 92:5659-5668.

Ranilla, M. J., and M. D. Carro. 2003. Diet and procedures used to detach particulate-associated microbes from ruminal digesta influence chemical composition of microbes and estimation of microbial growth in Rusitec fermenters. J. Anim. Sci. 81:537544

Roger, V., G. Fonty, S. Komisarczuk-Bony, and P. Gouet. 1990. Effects of physicochemical factors on the adhesion to cellulose Avicel of the ruminal bacteria Ruminococcus flavefaciens and Fibrobacter succinogenes ssp. succinogenes. Appl. Environ. Microbiol. 56:3081-3087.

Santra, A., S. A. Karim, A. S. Mishra, O. H. Chaturvedi, and R. Prasad. 1998. Rumen ciliate protozoa and fiber digestion in sheep and goats. Small Rumin. Res. 30:13-18.

Shannon, C. E., and W. Weaver. 1949. The Mathematical Theory of Communication. University of Illinois Press, Urbana.

Slyter, L. L., and P. A. Putnam. 1967. In vivo vs. in vitro continuous culture of ruminal microbial populations. J. Anim. Sci. 26:14211427.

Spanish Government. 2005. Royal Decree 1201/2005 for the protection of animals used for experimental and other scientific purposes of October 10th, BOE 252. Pages 34367-34274.

Stewart, C. S., H. J. Flint, and M. P. Bryant. 1997. The rumen bacteria. Pages 10-72 in The Rumen Microbial Ecosystem. P. N. Hobson and C. S. Stewart, ed. Chapman and Hall, London, UK.

Sylvester, J. T., S. K. R. Karnati, B. A. Dehority, M. Morrison, G. L. Smith, N. R. St-Pierre, and J. L. Firkins. 2009. Rumen ciliated 
protozoa decrease generation time and adjust 18S ribosomal DNA copies to adapt to decreased transfer interval, starvation, and monensin. J. Dairy Sci. 92:256-269.

Teather, R. M., and F. D. Sauer. 1988. A naturally compartmented rumen simulation system for the continuous culture of rumen bacteria and protozoa. J. Dairy Sci. 71:666-673.

Welkie, D. G., D. M. Stevenson, and P. J. Weimer. 2010. ARISA analysis of ruminal bacterial community dynamics in lactating dairy cows during the feeding cycle. Anaerobe 16:94-100.

Williams, P. P., R. E. Davis, R. N. Doetsch, and J. Guiterrez. 1961. Physiological studies of the rumen protozoan Ophryoscolex caudatus Eberlein. Appl. Microbiol. 9:405-409.
Yu, Z., and M. Morrison. 2004. Improved extraction of PCR-quality community DNA from digesta and fecal samples. Biotechniques $36: 808-812$.

Ziemer, C. J., R. Sharp, M. D. Stern, M. A. Cotta, T. R. Whitehead, and D. A. Stahl. 2000. Comparison of microbial populations in model and natural rumens using $16 \mathrm{~S}$ ribosomal RNA-targeted probes. Environ. Microbiol. 1:632-643. 